\title{
Artery buckling affects the mechanical stress in atherosclerotic plaques
}

\author{
Arnav Sanyal ${ }^{1}$, Hai-Chao Han²*
}

\footnotetext{
* Correspondence: hchan@utsa.edu ${ }^{2}$ Department of Mechanical Engineering, The University of Texas at San Antonio, San Antonio, TX 78249, USA
}

\begin{abstract}
Background: Tortuous arteries are often seen in patients with hypertension and atherosclerosis. While the mechanical stress in atherosclerotic plaque under lumen pressure has been studied extensively, the mechanical stability of atherosclerotic arteries and subsequent effect on the plaque stress remain unknown. To this end, we investigated the buckling and post-buckling behavior of model stenotic coronary arteries with symmetric and asymmetric plaque.

Methods: Buckling analysis for a model coronary artery with symmetric and asymmetric plaque was conducted using finite element analysis based on the dimensions and nonlinear anisotropic materials properties reported in the literature.

Results: Artery with asymmetric plaque had lower critical buckling pressure compared to the artery with symmetric plaque and control artery. Buckling increased the peak stress in the plaque and led to the development of a high stress concentration in artery with asymmetric plaque. Stiffer calcified tissue and severe stenosis increased the critical buckling pressure of the artery with asymmetric plaque.

Conclusions: Arteries with atherosclerotic plaques are prone to mechanical buckling which leads to a high stress concentration in the plaques that can possibly make the plaques prone to rupture.
\end{abstract}

\section{Background}

The rupture of atherosclerotic plaques in coronary arteries leads to thrombus occlusion and heart attack. Similarly, the rupture of atherosclerotic plaques in carotid arteries leads to cerebral occlusion and strokes. Due to the severe consequences of plaque rupture and the risk in interventional treatment, it is of critical clinical importance to identify vulnerable plaques. Myriads of clinical and basic studies have demonstrated that the rupture of plaque depends on the morphology, components, and biological environment of the plaque [1-3]. Yet, the mechanism of plaque rupture has not been fully understood.

Extensive biomechanical studies have shown that mechanical stress concentrations in plaques play a critical role in the rupture of plaques [4-6]. The stress in the plaque is determined by the geometry of the plaque, the composition and structure of the plaque, as well as the mechanical loads including the lumen pressure and axial stretch [7-9]. However, the effect of mechanical instability i.e. artery buckling on plaque stress has not been investigated.

Atherosclerotic carotid arteries are often tortuous but the mechanism of their tortuosity remains unclear [10-12]. We have previously showed that arteries buckle under lumen pressure and axial tension making them tortuous, thereby affecting the wall stress

C 2015 Sanyal and Han licensee BioMed Central Ltd. This is an Open Access article distributed under the terms of the Creative Commons Attribution License (http://creativecommons.org/licenses/by/4.0), which permits unrestricted use, distribution, and reproduction in any medium, provided the original work is properly cited. The Creative Commons Public Domain Dedication waiver (http://creativecommons.org/publicdomain/zero/1.0/) applies to the data made available in this article, unless otherwise stated. 
distribution in the vessel wall [13-16]. It is important to understand the relationship between artery tortuosity and stress in atherosclerotic plaque. Previous work by Tang and colleagues has demonstrated that cyclic bending of coronary arteries can increase the peak stress in atherosclerotic plaque $[17,18]$. Therefore, it is necessary to study the buckling stability of atherosclerotic arteries and understand its possible effect on the mechanical stress in the plaques.

Accordingly, the objective of this study was to investigate the buckling behavior of arteries with atherosclerotic plaques and the subsequent effects on the mechanical stress in plaques.

\section{Methods}

We performed a structural finite element analysis to simulate the buckling and postbuckling behavior of a coronary artery with symmetric and asymmetric (eccentric) atherosclerotic plaque. The effect of plaque on arterial stability was evaluated by comparing the critical buckling pressure and the maximum stress developed in the normal artery and the stenotic artery with plaque.

A cylindrical model of coronary artery was created using Solidworks ${ }^{\circledR}$ (Dassault Systèmes, Waltham, MA). The unloaded vessel had a dimension of length $60 \mathrm{~mm}$, outer diameter of $6 \mathrm{~mm}$ and wall thickness of $1 \mathrm{~mm}$ based on previous reports $[17,19]$. Atherosclerotic plaque models were created in the middle of the artery and the plaque geometry was either symmetric or asymmetric with respect to the artery axis (Figure 1(a)). The plaque was assumed to consist of a lipid pool and calcified tissue surrounded by a thin fibrous cap (cap thickness $=0.5 \mathrm{~mm}$ ). The diameter of the throat of the plaque $(2 \mathrm{~mm})$ was half the diameter of the lumen $(4 \mathrm{~mm})$, resulting in a stenosis severity of $75 \%$ by cross-sectional area [20].

The arterial wall was assumed to behave as a homogenous, incompressible, orthotropic, nonlinear material with the Fung strain energy function of the form [21]:

$$
W=\frac{b_{0}}{2} e^{Q}
$$

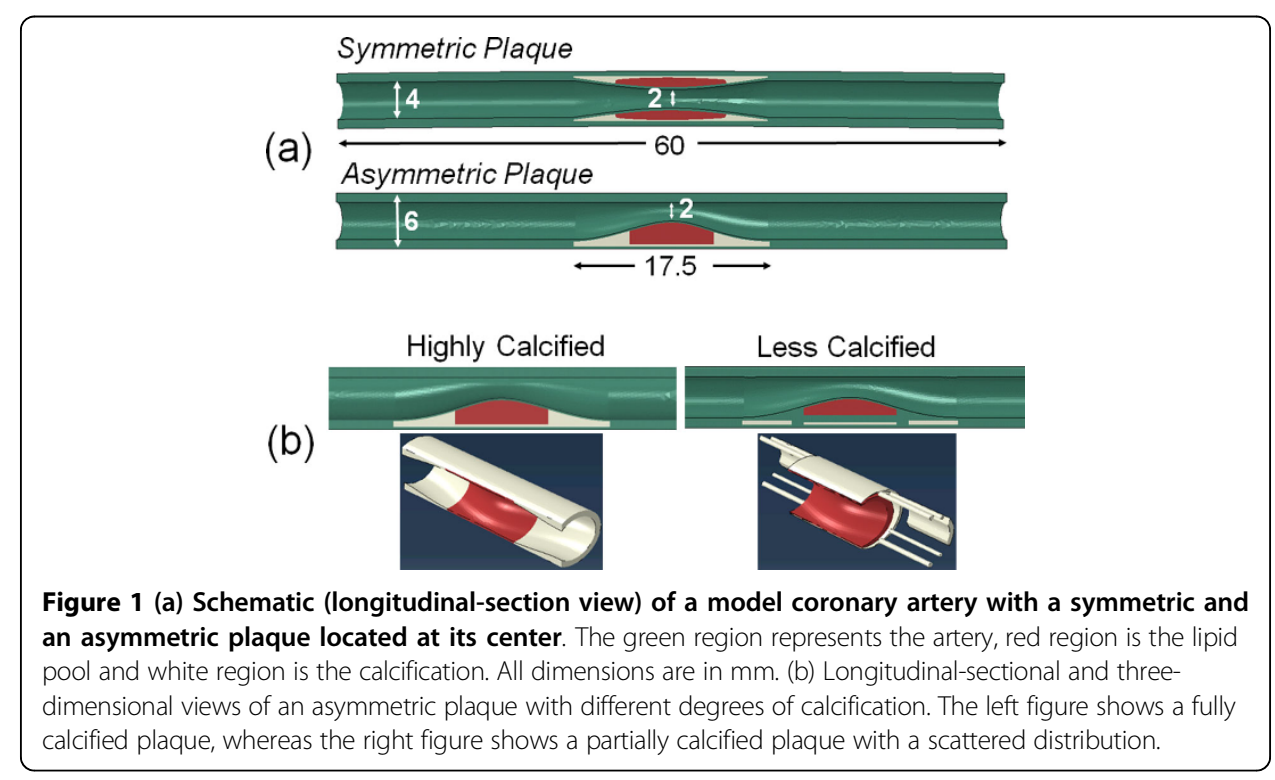




$$
Q=b_{1} E_{\theta}^{2}+b_{2} E_{z}^{2}+b_{3} E_{r}^{2}+2 b_{4} E_{\theta} E_{z}+2 b_{5} E_{z} E_{r}+2 b_{6} E_{\theta} E_{r}
$$

where $b_{0}, b_{1}, b_{2}, b_{3}, b_{4}, b_{5}, b_{6}$ are material constants from Wang et.al [22] (Table 1). The fibrous cap was also assumed to have the same material property as that of the artery. The lipid pool and calcified tissue were assumed to behave as incompressible, isotropic material with the neo-Hookean strain energy function. The stiffness of the lipid pool and the calcified tissue were assumed to be one-tenth and ten times the stiffness of the artery wall, respectively [17]:

$$
\mathrm{W}=\mathrm{C}\left(\mathrm{I}_{1}-3\right)
$$

with $\mathrm{C}_{\text {lipid }}=0.1 \mathrm{~b}_{0}$ and $\mathrm{C}_{\text {calcified-tissue }}=10 \mathrm{~b}_{0}$

The buckling behavior of all arterial models (normal control, stenotic with symmetric plaque, or with asymmetric plaque) was simulated using the commercial FEA package ABAQUS $^{\circledR}$ (v6.11, Dassault Systèmes, Waltham, MA). The models were meshed using hybrid quadratic tetrahedral elements. Since coronary arteries are generally under very little axial pre-stretch [23,24], an axial displacement equivalent to a stretch ratio of 1.05 (i.e. 5\% axial stretch) was applied to all nodes at the distal end of the arteries. A static internal pressure was applied to the lumen of the arterial models and the external pressure was set at zero. Both ends of the arteries were assumed as fixed with no lateral displacement or rotation, but were allowed to expand radially. These end conditions simulated the expansion of arteries under pressure in vivo and minimized the possible edge effects at the ends [25]. A small initial bend of 1 degree along the central axis of the normal artery model and the symmetric plaque model was created as an imperfection to facilitate the buckling analysis. The maximum lateral deflection of the central axis of artery was determined by averaging the deflections of two edges of the artery wall at the mid-point of the artery and was plotted against the lumen pressure. The pressure at which the deflection starts to increase from baseline and reaches a value of $0.5 \mathrm{~mm}$ was defined as the critical buckling pressure $[15,26]$.

To determine the effect of buckling on maximum stress developed in the plaque, we compared two stenotic artery models with symmetric plaques, but different neck lengths (a long neck with length $=60 \mathrm{~mm}$ and a short neck with length $=30 \mathrm{~mm}$ ). With the different neck lengths, the two models had different critical buckling pressures, such that at physiological pressures, the atherosclerotic vessel with long neck buckled while the control one with the short neck remained unbuckled. This approach allows us to specify the effect of buckling on plaque stress since the pressure and axial stretch ratio all remain the same in both models.

To determine the effect of amount of calcification and size of the lipid pool, an additional model of an asymmetric plaque was created with a smaller volume of the calcified tissue and lipid pool. The calcified tissue had a scattered distribution as shown in Figure 1(b).

A sensitivity analysis was performed to determine the effect of change of stiffness of plaque components on the buckling behavior of the asymmetric plaque model. The

Table 1 Material constants of the Fung's exponential strain energy function for the artery used in model simulations (from [20])

\begin{tabular}{ccccccc}
\hline $\mathbf{b}_{\mathbf{0}}(\mathbf{k P a})$ & $\mathbf{b}_{\mathbf{1}}$ & $\mathbf{b}_{\mathbf{2}}$ & $\mathbf{b}_{\mathbf{3}}$ & $\mathbf{b}_{\mathbf{4}}$ & $\mathbf{b}_{\mathbf{5}}$ & $\mathbf{b}_{\mathbf{6}}$ \\
\hline 29.01 & 0.61 & 1.53 & 0.44 & 0.32 & 0.06 & 0.12 \\
\hline
\end{tabular}


modulus of the lipid pool and calcified tissue (constant $\mathrm{C}$ in equation (2)) of the asymmetric plaque model was varied by $\pm 50 \%$ from their baseline values [20]. Another analysis was performed to determine the effect of stenosis severity. The throat diameter of the asymmetric plaque model was changed to $1.2 \mathrm{~mm}$ and $2.8 \mathrm{~mm}$ resulting in stenosis severity of $90 \%$ (more stenosis) and $50 \%$ (less stenosis) by cross-sectional area, respectively. In all these simulations, the boundary conditions were kept the same as described above and the deflections were determined for increasing lumen pressures. The deflections were then plotted with the pressure and the critical buckling pressure was determined as described above.

\section{Results}

The presence of an atherosclerotic plaque affects the critical buckling pressure of a coronary artery. The buckling behavior of the stenotic artery with plaque was different from the normal artery and different for symmetric and asymmetric plaques. The stenotic artery with a symmetric plaque had a critical buckling pressure $(7.0 \mathrm{kPa})$ close to that of a normal artery $(6.9 \mathrm{kPa})$. However, the stenotic artery with an asymmetric plaque had a much lower critical buckling pressure (5.5 kPa) (Figure 2). The post-buckling deflection increased rapidly for the stenotic artery with asymmetric plaque compared to normal artery, whereas stenotic artery with symmetric plaque had a slightly slower rise in the deflection.

For the artery with a symmetric plaque, the maximum stress developed in the buckled artery was larger than that of the unbuckled artery (Figure 3). The stress in the plaque for the buckled artery increased much more significantly with an increase in the lumen pressure (Figure 4).

The symmetry of the plaque (symmetric or asymmetric) had a significant effect on the location and magnitude of peak stress in the plaque post-buckling (Figure 5). At a physiological lumen pressure of $100 \mathrm{mmHg}$, the maximum stress in the symmetric plaque model was observed in the calcified tissue and its magnitude was $32 \%$ higher than the maximum stress in the lumen of the normal artery (305 kPa vs $234 \mathrm{kPa}$ ). However, the maximum stress in the asymmetric model was observed in the fibrous cap located slightly away from the center of the artery and had almost four-fold higher magnitude (960 kPa).

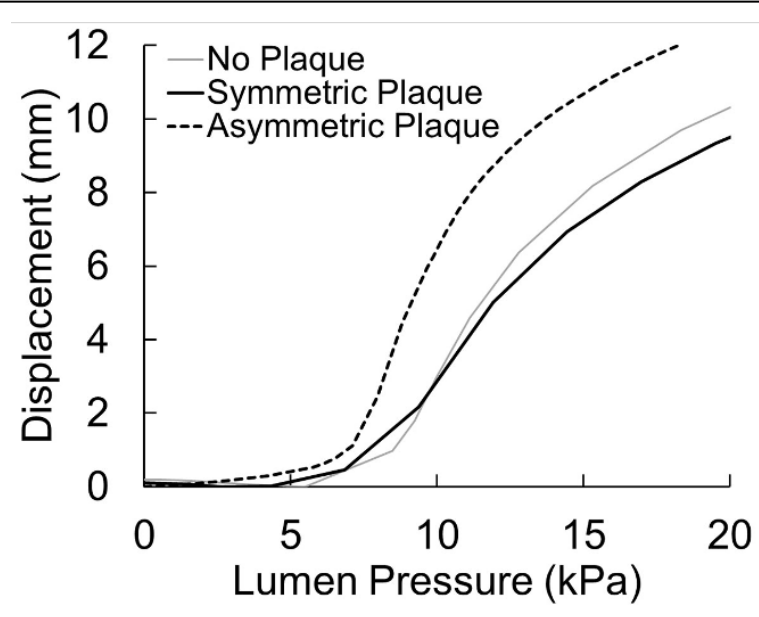

Figure 2 Buckling displacement (maximum deflection at the middle) plotted as function of lumen pressure of a normal artery, artery with symmetric plaque, and artery with an asymmetric plaque. 

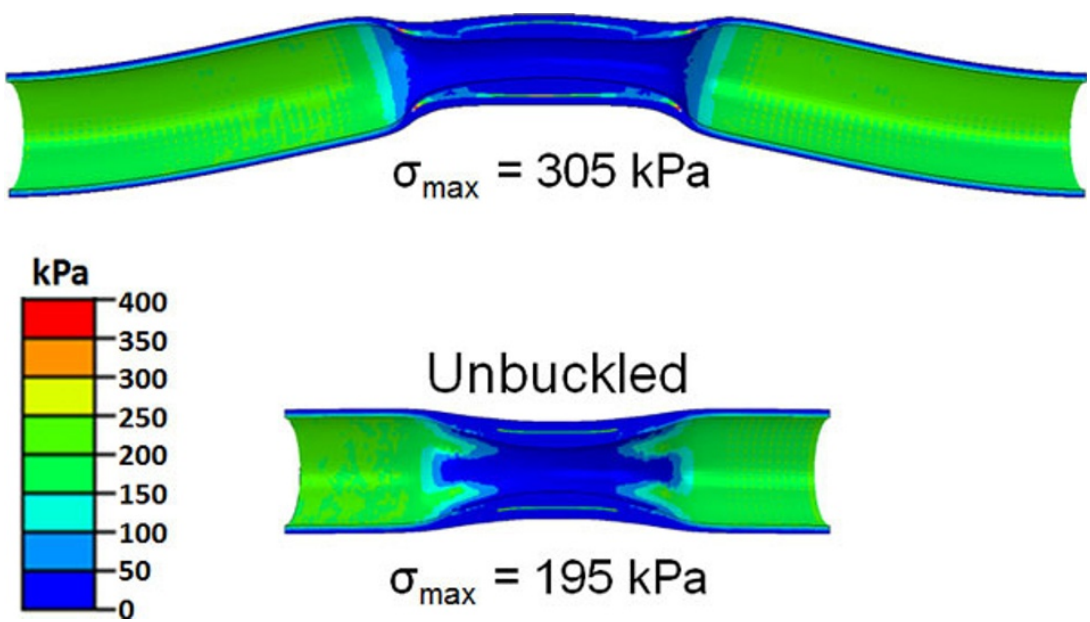

Figure 3 von Mises stress profile in buckled and unbuckled artery with a symmetric plaque under the same lumen pressure of $100 \mathrm{mmHg}(13.33 \mathrm{kPa})$. The neck was cut short in the bottom model to avoid buckling.

Also, the maximum stress in the asymmetric plaque model increased much more rapidly with increasing lumen pressure compared to the symmetric plaque model (Figure 6).

An interesting observation was that for asymmetric plaque of major lipid pool and major calcification cores, the buckling direction could be different and thus the stress pattern/distribution could be different. A less calcified asymmetric plaque deflects almost immediately after pressure is applied (near-zero critical buckling pressure) and the deflection is towards the side of the plaque. In contrast, a highly calcified asymmetric plaque buckles at a certain critical buckling pressure. Moreover, the deflection is towards the opposite side of the plaque (Figures $7 \& 8$ ).

For the artery with asymmetric plaque, the change in stiffness of the lipid pool by $\pm 50 \%$ had negligible effect on both the critical buckling pressure and the maximum stress in the fibrous cap at $100 \mathrm{mmHg}$ lumen pressure (Figure 9). However, a 50\% increase in the stiffness of calcified tissue resulted in $7 \%$ higher buckling pressure $(5.9 \mathrm{kPa})$ and $4 \%$ lower stress in the fibrous cap (922 kPa). Similarly, a 50\% decrease in the stiffness of the calcified

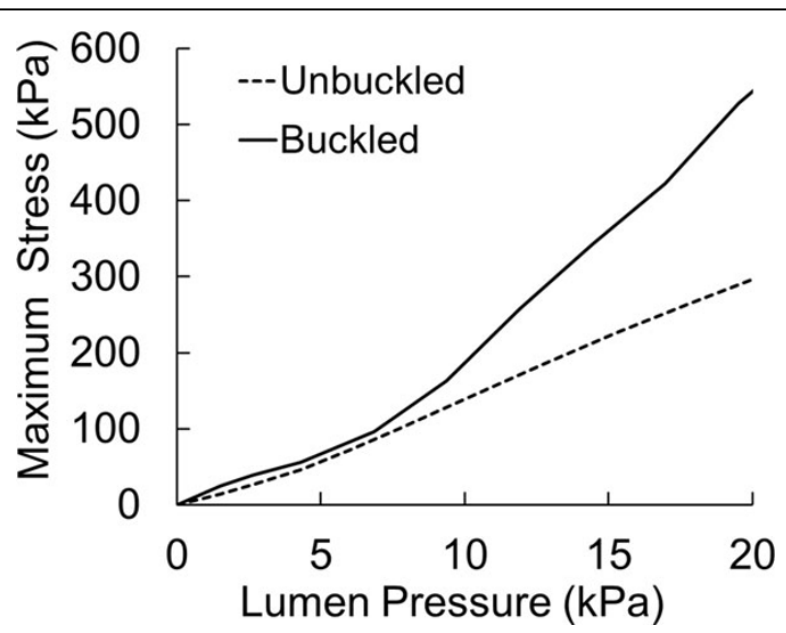

Figure 4 Comparison of peak von Mises stress as a function of lumen pressure for a buckled and an unbuckled artery with symmetric plaque. 


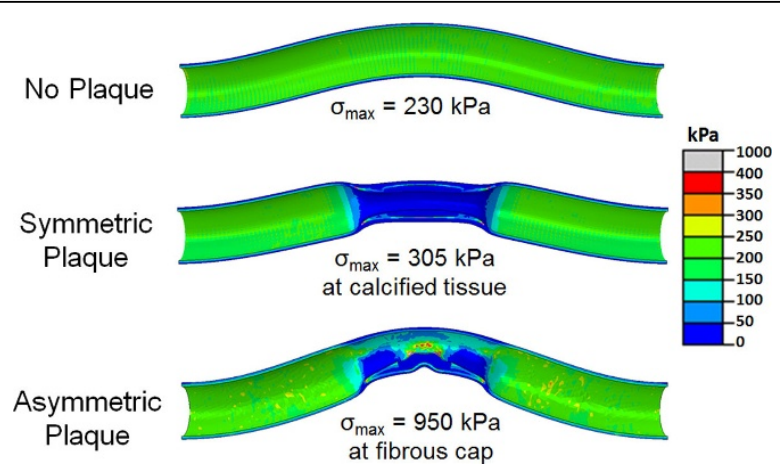

Figure 5 von Mises stress distribution in the artery lumen and the plaque (longitudinal-section view) for a normal artery, artery with symmetric plaque and artery with asymmetric plaque at a lumen pressure of $100 \mathrm{mmHg}$.

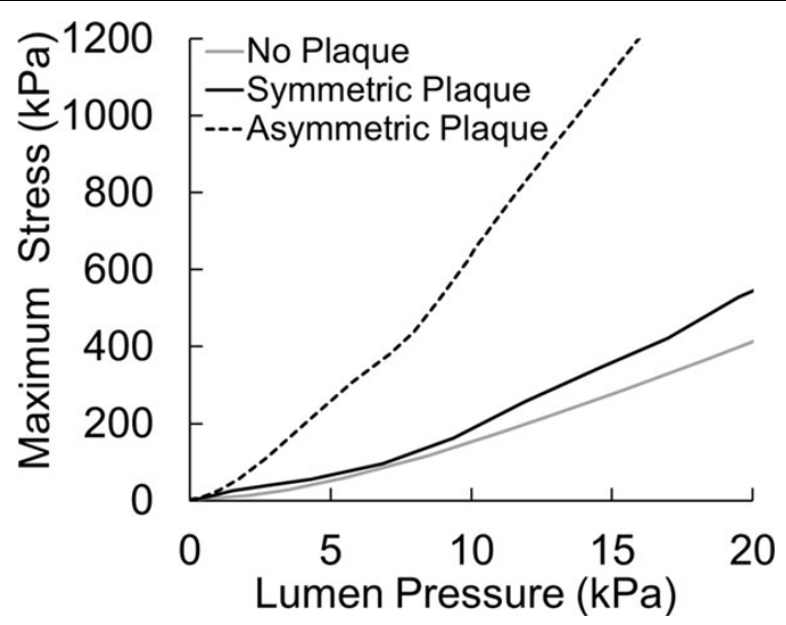

Figure 6 Peak von Mises stress plotted as a function of lumen pressure for a normal artery and stenotic artery with symmetric and asymmetric plaques.

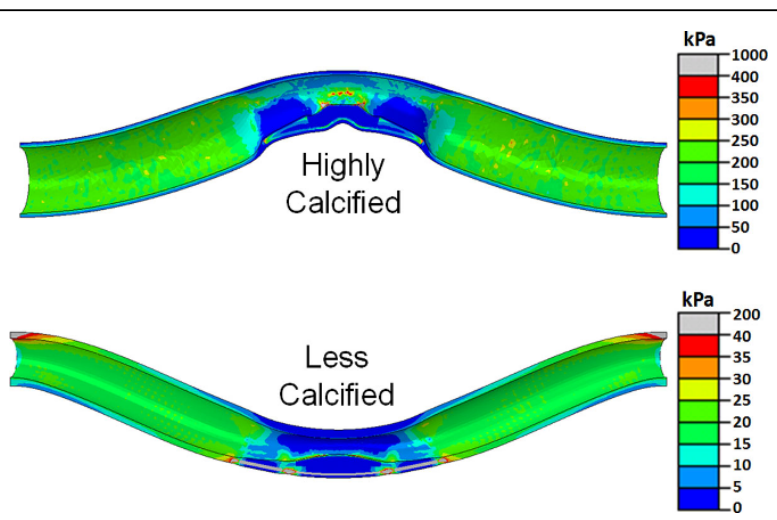

Figure 7 Deformed shape and stress distribution in the plaque and lumen of an artery with asymmetric plaques with different degrees of calcification. The maximum deflection in both cases is around $11 \mathrm{~mm}$ but at different lumen pressures (see Figure 8). Note the ten-fold difference in the scales of the two stress maps. 


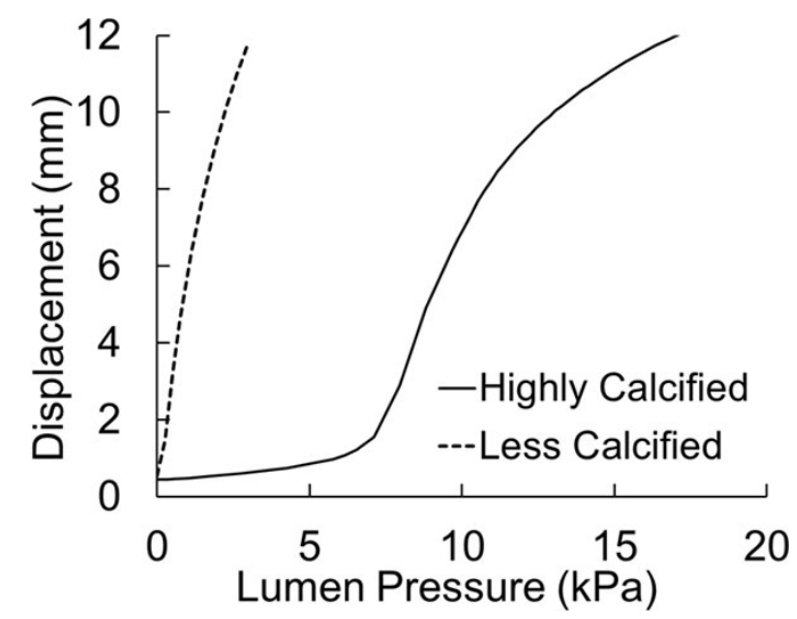

Figure 8 Buckling deflections plotted as functions of lumen pressure of arteries with asymmetric plaque with different degrees of calcification.

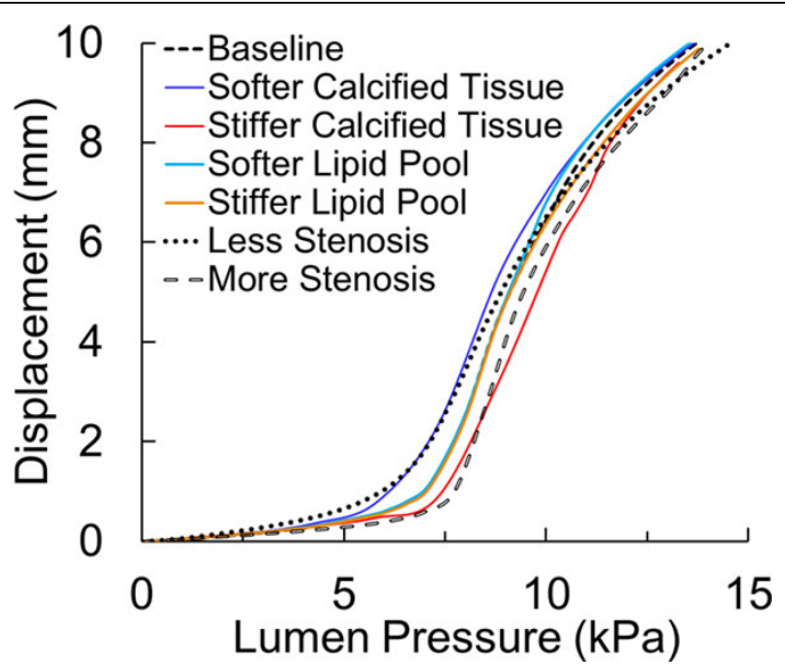

Figure 9 Buckling deflection plotted as a function of lumen pressure for the artery with an asymmetric plaque (baseline model) and its several variations of stiffness of calcified tissue, stiffness of lipid pool and stenosis severity. The baseline model had material properties as per equation (2) and had a stenosis severity of $75 \%$ by cross-sectional area.

tissue resulted in $13 \%$ lower critical buckling pressure (4.8 kPa) and a $2.5 \%$ higher stress in fibrous cap $(983 \mathrm{kPa})$.

The reduction of stenosis severity from $75 \%$ to $50 \%$ in terms of cross-sectional area resulted in $22 \%$ lower critical pressure $(4.4 \mathrm{kPa})$ and a $60 \%$ reduction in the stress at the fibrous cap (382 $\mathrm{kPa})$. However, increasing the stenosis severity to $90 \%$ resulted in $20 \%$ higher critical pressure $(6.6 \mathrm{kPa})$ but only $3 \%$ decrease in stress at the fibrous cap $(929 \mathrm{kPa})$ (Figure 9).

\section{Discussion}

The results of this study show that stenotic arteries with atherosclerotic plaques are prone to mechanical buckling which can make them tortuous and lead to high stresses in the plaque. In addition, buckling leads to a faster rise in plaque stress with 
increasing pressure. The amount of calcification alters the local rigidity of the plaque and therefore affects the buckling deflection pattern and stress distribution in the plaque and artery. The change in stiffness of the calcified tissue and the stenosis severity has a noticeable effect on the buckling behavior and stress distribution in atherosclerotic plaque.

Our results are consistent with results from previous studies. Most plaques are eccentric and their rupture is most likely due to failure of the thin fibrous cap [3] which is consistent with our current simulation results. Tang et al. $[17,18]$ demonstrated that cyclic bending had a significant effect on the development of high stress in the plaque, which is consistent with our observation that bent buckling of an artery results in a rapid rise in plaque stress. Our previous study on buckling of arteries with fusiform aneurysms also showed the significance of bent buckling in development of tortuosity and high stress concentration in aneurysm wall $[27,28]$. Recently, Abdelali et al. [29] demonstrated that the thin fibrous cap of atherosclerotic cap itself can buckle locally into a wavy shape. Our simulation of asymmetric plaque shows similar deformed shape with local buckling of the cap of the lipid pool. Furthermore, we also showed that there is a global buckling pattern of the whole artery segment, which leads to high stresses in the fibrous cap. Therefore, our results suggest that mechanical buckling makes atherosclerotic arteries tortuous and is an important factor that affects the plaque stress, which may lead to plaque rupture. In addition, Weinbaum and colleagues have recently demonstrated that scattered calcium cores can lead to high stress concentrations which can cause plaque rupture [30-32]. Similarly, our simulations showed that the scattered calcium cores also affect the buckling of artery with plaques and can alter the stress distribution in the plaque.

One limitation of this study was that we considered an idealized geometric model of the coronary artery and the plaque as well as simplified boundary conditions. The initial curvature of the artery was not considered and the arterial wall was assumed as homogenous. A previous study has shown that the effect of initial curvature on artery buckling is small [33]. In addition, the surrounding tissue support was not considered and the two ends of the artery were assumed to be fixed. These are idealized representation of the limited support available for coronary arteries in vivo since these arteries align on the surface of the myocardial wall. Changing the boundary constraints may lead to higher critical buckling pressures and different bucking patterns $[14,34]$ which may affect the local curvature of the plaque and therefore the stress levels in the plaque. Secondly, the stress and buckling analysis done under static pressure. Previous studies have demonstrated that the buckling peak pressure and stress follow similar trends as demonstrated under static pressure, though the stress will be cyclic during a cardiac cycle $[26,35,36]$. The severity of stenosis will also affect the blood flow in the throat of the plaque with a local reduction in pressure. Such effects can be studied in the future using computational models with fluid-structure interaction [5,17]. In addition, the variations of lipid pool size and fibrous cap thickness, which may change the magnitude of the maximum stress and stress distribution in the plaque were not examined and needs further investigation. Despite these limitations, this study shows the susceptibility of stenotic artery to buckling which can lead to a higher peak stress.

The development of high peak stress in atherosclerotic plaque has been considered as a trigger for plaque rupture [4-6]. Thus, our simulation results suggest that the presence of an asymmetric-shaped or eccentric plaque can make artery more susceptible 
to rupture due to the development of high stress concentration in the fibrous cap of the plaque.

\section{Conclusion}

Arteries with atherosclerotic plaques are prone to mechanical buckling which leads to a high stress concentration in the plaques that could possibly make the plaques prone to rupture. Mechanical buckling of the atherosclerotic plaque and the arterial wall could be a new factor that needs to be considered in studying the biomechanics of plaque rupture.

Competing interests

The authors declare that they have no competing interests.

\section{Authors' contributions}

$\mathrm{HCH}$ : study design, data analysis, and manuscript preparation, AS: finite element analysis, data analysis and manuscript preparation. All authors read and approved the final manuscript.

\section{Acknowledgements}

This work was supported by grant HL095852 from the National Institutes of Health. We thank the Computational Systems Biology Core at UTSA funded by the National Institutes of Health through grant G12MD007591.

\section{Declaration}

Publication of this article was paid with funding from grant HL095852 from the National Institutes of Health. This article has been published as part of BioMedical Engineering OnLine Volume 14 Supplement 1, 2015: Cardiovascular Disease and Vulnerable Plaque Biomechanics. The full contents of the supplement are available online at http://www.biomedical-engineering-online.com/supplements/14/S1

\section{Authors' details}

'Department of Mechanical Engineering The University of Texas at San Antonio Biomedical Engineering Program, UTSA-UTHSCSA, TX, USA. ${ }^{2}$ Department of Mechanical Engineering, The University of Texas at San Antonio, San Antonio, TX 78249, USA.

\section{Published: 9 January 2015}

\section{References}

1. Akyildiz AC, Speelman L, van Brummelen H, Gutierrez MA, Virmani R, van der Lugt A, van der Steen AF, Wentzel JJ, Gijsen FJ: Effects of intima stiffness and plaque morphology on peak cap stress. Biomed Eng Online 2011, 10:25.

2. Arroyo LH, Lee RT: Mechanisms of plaque rupture: mechanical and biologic interactions. Cardiovasc Res 1999, 41(2):369-375.

3. Cardoso L, Weinbaum S: Changing views of the biomechanics of vulnerable plaque rupture: a review. Ann Biomed Eng 2014, 42(2):415-431.

4. Cheng GC, Loree HM, Kamm RD, Fishbein MC, Lee RT: Distribution of circumferential stress in ruptured and stable atherosclerotic lesions. A structural analysis with histopathological correlation. Circulation 1993, 87(4):1179-1187.

5. Tang D, Teng Z, Canton G, Yang C, Ferguson M, Huang X, Zheng J, Woodard PK, Yuan C: Sites of rupture in human atherosclerotic carotid plaques are associated with high structural stresses: an in vivo MRI-based 3D fluid-structure interaction study. Stroke 2009, 40(10):3258-3263.

6. Holzapfel GA, Mulvihill JJ, Cunnane EM, Walsh MT: Computational approaches for analyzing the mechanics of atherosclerotic plaques: a review. J Biomech 2014, 47(4):859-869.

7. Huang $H$, Virmani $R$, Younis $H$, Burke AP, Kamm RD, Lee RT: The impact of calcification on the biomechanical stability of atherosclerotic plaques. Circulation 2001, 103(8):1051-1056.

8. Rambhia SH, Liang X, Xenos M, Alemu Y, Maldonado N, Kelly A, Chakraborti S, Weinbaum S, Cardoso L, Einav S, Bluestein D: Microcalcifications increase coronary vulnerable plaque rupture potential: a patient-based micro-CT fluid-structure interaction study. Ann Biomed Eng 2012, 40(7):1443-1454.

9. Li ZY, Howarth SP, Tang T, Gillard JH: How critical is fibrous cap thickness to carotid plaque stability? A flow-plaque interaction model. Stroke 2006, 37(5):1195-1199.

10. Han HC: Twisted Blood Vessels: Symptoms, Etiology, and Biomechanical Mechanisms. J Vasc Res 2012, 49(3):185-197.

11. Del Corso L, Moruzzo D, Conte B, Agelli M, Romanelli AM, Pastine F, Protti M, Pentimone F, Baggiani G: Tortuosity, kinking, and coiling of the carotid artery: expression of atherosclerosis or aging? Angiology 1998, 49(5):361-371.

12. Pancera P, Ribul M, Presciuttini B, Lechi A: Prevalence of carotid artery kinking in 590 consecutive subjects evaluated by Echocolordoppler. Is there a correlation with arterial hypertension? I Intern Med 2000, 248(1):7-12.

13. Datir P, Lee AY, Lamm SD, Han HC: Effects of Geometric Variations on the Buckling of Arteries. International journal of applied mechanics 2011, 3(2):385-406.

14. Han HC: Blood vessel buckling within soft surrounding tissue generates tortuosity. J Biomech 2009, 42(16):2797-2801.

15. Lee AY, Han B, Lamm SD, Fierro CA, Han HC: Effects of elastin degradation and surrounding matrix support on artery stability. Am J Physiol Heart Circ Physiol 2012, 302(4):H873-884. 
16. Han HC: A biomechanical model of artery buckling. J Biomech 2007, 40(16):3672-3678

17. Tang D, Yang C, Kobayashi S, Zheng J, Woodard PK, Teng Z, Billiar K, Bach R, Ku DN: 3D MRI-based anisotropic FSI models with cyclic bending for human coronary atherosclerotic plaque mechanical analysis. J Biomech Eng 2009, 131(6):061010.

18. Yang C, Tang D, Kobayashi S, Zheng J, Woodard PK, Teng Z, Bach R, Ku DN: Cyclic Bending Contributes to High Stress in a Human Coronary Atherosclerotic Plaque and Rupture Risk: In Vitro Experimental Modeling and Ex Vivo MRI-Based Computational Modeling Approach. Mol Cell Biomech 2008, 5(4):259-274.

19. Waller BF, Orr CM, Slack JD, Pinkerton CA, Van Tassel J, Peters T: Anatomy, histology, and pathology of coronary arteries: a review relevant to new interventional and imaging techniques-Part IV. Clin Cardiol 1992, 15(9):675-687.

20. Tang D, Yang C, Zheng J, Woodard PK, Saffitz JE, Sicard GA, Pilgram TK, Yuan C: Quantifying effects of plaque structure and material properties on stress distributions in human atherosclerotic plaques using 3D FSI models. J Biomech Eng 2005, 127(7):1185-1194.

21. Fung YC: Biomechanics: Mechanical Properties of Living Tissues. 2 edition. New York: Springer Verlag; 1993.

22. Wang C, Garcia M, Lu X, Lanir Y, Kassab GS: Three-dimensional mechanical properties of porcine coronary arteries: a validated two-layer model. Am J Physiol Heart Circ Physiol 2006, 291(3):H1200-1209.

23. Han HC, Fung YC: Longitudinal strain of canine and porcine aortas. J Biomech 1995, 28(5):637-641.

24. Gasser TC, Holzapfel GA: Modeling plaque fissuring and dissection during balloon angioplasty intervention. Ann Biomed Eng 2007, 35(5):711-723.

25. Lee AY: Determining the Critical Buckling of Blood Vessels Through Modeling and In Vitro Experiments. PhD Doctoral Thesis University of Texas at San Antonio, Biomedical Engineering; 2011.

26. Liu Q, Han HC: Mechanical buckling of artery under pulsatile pressure. J Biomech 2012, 45(7):1192-1198.

27. Han HC, Shadfan RH, Xiao Y: Aneurismal arteries are vulnerable to mechanical buckling. ASME Summer Bioengineering Conference; June 26-29; Sunriver, Oregon, USA 2013.

28. Lee AY, Sanyal A, Xiao Y, Shadfan R, Han HC: Mechanical Instability of Normal and Aneurysmal Arteries. Journal of biomechanics 2014.

29. Abdelali M, Reiter S, Mongrain R, Bertrand M, L'Allier PL, Kritikou EA, Tardif JC: Cap buckling as a potential mechanism of atherosclerotic plaque vulnerability. J Mech Behav Biomed Mater 2014, 32:210-224.

30. Vengrenyuk Y, Carlier S, Xanthos S, Cardoso L, Ganatos P, Virmani R, Einav S, Gilchrist L, Weinbaum S: A hypothesis for vulnerable plaque rupture due to stress-induced debonding around cellular microcalcifications in thin fibrous caps. Proc Natl Acad Sci USA 2006, 103(40):14678-14683.

31. Kelly-Arnold A, Maldonado N, Laudier D, Aikawa E, Cardoso L, Weinbaum S: Revised microcalcification hypothesis for fibrous cap rupture in human coronary arteries. Proc Natl Acad Sci USA 2013, 110(26):10741-10746.

32. Cardoso L, Kelly-Arnold A, Maldonado N, Laudier D, Weinbaum S: Effect of tissue properties, shape and orientation of microcalcifications on vulnerable cap stability using different hyperelastic constitutive models. J Biomech 2014, 47(4):870-877.

33. Han HC: The mechanical buckling of curved arteries. Mol Cell Biomech 2009, 6(2):93-99.

34. Han HC: The theoretical foundation for artery buckling under internal pressure. J Biomech Eng 2009, 131(12):124501.

35. Rachev A: A theoretical study of mechanical stability of arteries. J Biomech Eng 2009, 131(5):051006.

36. Han HC, Chesnutt JK, Chesnutt JR, Liu Q, Wen Q: Artery buckling: new phenotypes, models, and applications. Ann Biomed Eng 2013, 41(7):1399-1410.

doi:10.1186/1475-925X-14-S1-S4

Cite this article as: Sanyal and Han: Artery buckling affects the mechanical stress in atherosclerotic plaques.

BioMedical Engineering OnLine 2015 14(Suppl 1):S4.

\section{Submit your next manuscript to BioMed Central and take full advantage of:}

- Convenient online submission

- Thorough peer review

- No space constraints or color figure charges

- Immediate publication on acceptance

- Inclusion in PubMed, CAS, Scopus and Google Scholar

- Research which is freely available for redistribution 